\title{
The Rubric: An Assessment Tool to Guide Students and Markers
}

\author{
G C Cox*, J Morrison**, B H Brathwaite*** \\ *Senior Lecturer, Middlesex University \\ **Lecturer, Middlesex University \\ ***Senior Lecturer, Hertfordshire University
}

\begin{abstract}
The changing environment for both students and lecturers dictates the requirement for giving feedback on assessment activities rapidly. In order to close this cycle of learning for the student and facilitate the feed-forward process, the development of rubrics has become an essential part of the workload. The rubric tool needs to have clearly stated performance indicators and criteria so that both student and lecturer have the same expectations of the assessment activity. The rubric must be robust enough to be able to capture the balance of being both an easy tool for marking but also detailed enough to give constructive feedback reflecting the learning outcomes. The rubric development, given its complexity, when constructing this tool, can be time consuming but eventually becomes time saving. Thereby reducing the grading workload effort of the lecturer while maintaining the knowledge gained by the students through the assessment activity.
\end{abstract}

Key words: Rubric; VLE; Performance Criteria; Feedback; Feedforward

\section{Introduction}

For the teaching and learning cycle, the word 'rubric' is understood generally to connote a simple assessment tool that describes levels of performance on a particular task and is used to assess outcomes in a variety of performance-based contexts' (Hafner and Hafner, 2003 p, 1509). The rubric as a marking tool and the virtual learning environment (VLE) have both worked their way into nursing education as 'new' way of teaching, learning and assessing students (Lai and Ng 2011). This allows both lecturer and student to develop as the facilitator and interpreter of knowledge and permitting clear ideas of what is expected from the assessment and what is achievable by the student. The rubric, unlike a marking template, is not only focused on giving guidance to marker but includes the student. With the marking templates there is greater capacity for and moreover, an inherent lack of uniformity and parity between markers, born out of each markers interpretation of the marking template. With the requirement of rapid turnaround times, transparent feedback to the student, combined with the ease of access via the VLE and the moderation process to be considered, a clear need has arisen to facilitate the marking process. The progressive movement of the use of technology and the easy access provided by online learning platforms, has created learning conditions where different aspects of feedback can be used (group, individual, audio), to ensure that the students learning is fluent and allows progression of the learning cycle.

Combine the introduction of a new degree nursing curriculum in England (Nursing and Midwifery Council 2010), with the university's e-assessment strategy, and this brought an opportunity to review models of learning and teaching focussing on:-

1. How the student could engage in different ways of learning (e.g. Discussion boards, the flipped classroom, digital stories)

2. The capabilities of VLE (does it do what the lecturer wants?)

3. How best to facilitate submission and feedback within this environment. 
The ideology behind the VLE is to create an engaging learning environment in which students can participate, while they are effectively developing 'clear thinking' and promoting an interactive learning experience (Lewis et al., 2012). Therefore it is of paramount importance to give clear concise performance criteria and provide a forum in which students can create their own learning opportunities. Thus enabling the learner to build a genuine comprehension of the subject matter so they can foster confidence and research skills when conveying their ideas and opinions on a topic, (Pucer et al., 2014). Given these criteria, it becomes imperative that both the lecturer and student have a clear understanding of the performance indicators, hence why the rubric was considered important tool.

\section{The Advantages and Disadvantages of Rubrics}

Andrade and Du (2005) advocate that a rubric as an assessment tool should be used by the student and assessor to give both parties clear understanding of what is expected by either doing task or grading the assessment. This aims to ensure achieving learning outcomes and activating a feed forward mechanism through concise information on how to improve performance whilst enabling student's time to reflect on their work (Truemper 2005).This reflective ethos on work produced, fosters communication and the learning cycle to be completed.

There are many different debates surrounding the use of the rubric tool as an assessment and communication tool, as the themes become clear with the use of parity and gives guidance this is evident from school age to higher education nursing and non-nursing education (Andrade and Du 2005; Caulfield-Sloan and Ruzcika; Hafner and Hafner 2003; Truemper 2004). Mandills et al (2009) support the use of rubrics in primary, secondary, further and higher education context as the grading is seen to be fairer and more consistent. While Beaglehole (2014) focuses on students of school age children in Australia and encourages that clear and specific goals for writing are highly effective.

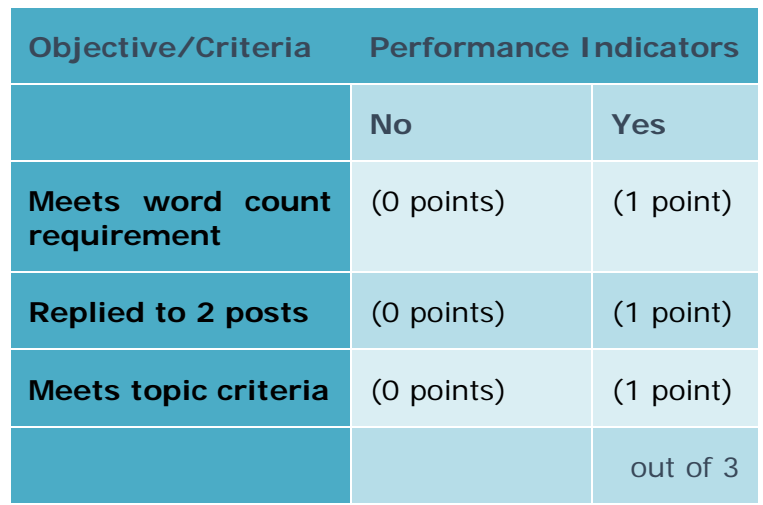

Figure 1 Rubric 1

The rubric as an assessment tool can be either presented as a simple Rubric [yes /no performance indicators Figure1], as was adopted, for example for a non-graded formative discussion board or as a complex Rubric [descriptive banded performance indicators: unsatisfactory, pass, good, very good \& excellent, Figure 2], as it should reflect the assessment learning outcomes (Popham 1997) and should be presented with no confusion of the learning opportunity that needs to be taking place for the student (Vallino 2008). Oppositely, for the marker the rubric should be a tool that is ultimately relies on the ability, knowledge and preparation of the assessor this will be enhanced with the familiarity of the performance criteria.

The other advantage of the rubric when marking is its focus on the specific criteria that the students have to attain for the module (Truemper 2003). Fors and Gunning (2014) 
suggests that the Rubric needs to present a clear set of assignment descriptions/categories and have levels of performance indicators that are the evaluation dimension which may or may not hold a numerical value to them. The

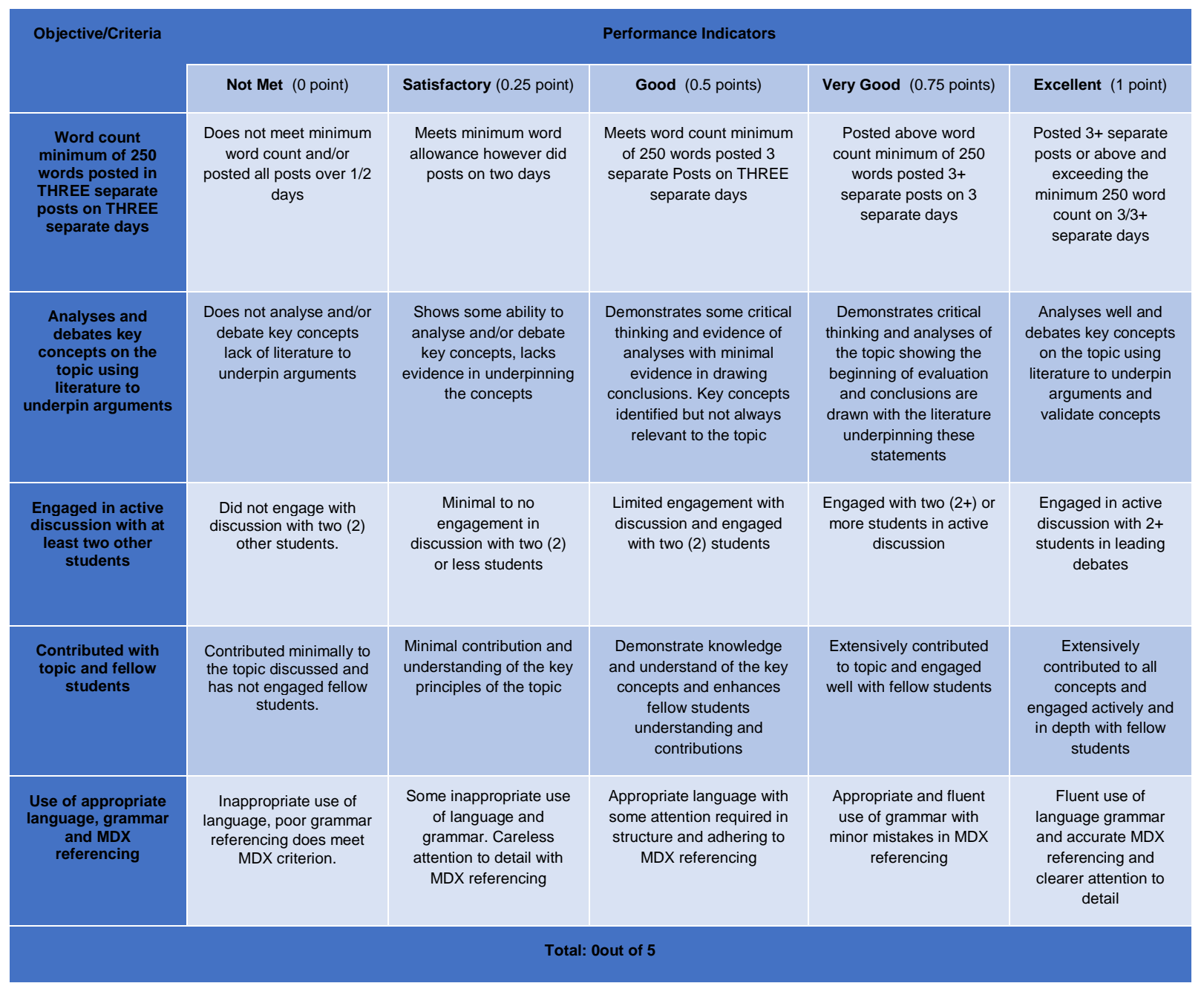

Figure 2 Rubric 2 Complex

indicators are the different categories that the students are required to meet and the performance indicators represent how well these have been achieved.

Rubrics fall into two categories, either 'analytical or multiple trait consisting of multiple, separate scales and therefore provides a set of scores' (Rezaei and Lovorn 2010 p19; Dunbar et al 2006). This loans itself to different types of teaching and assessment strategies enabling use of different tools to assess different aspects of what is required from the student. A holistic rubric will look at the elements combined and give an overall impression of the learning to be achieved, (Dunbar et al 2006; Truemper 2004). It has been agreed that rubric is not simply a checklist or just a checklist (Andrade 2005; Petkov and Petkov 2006). A rubric is only as good as its design, support and explanation in its use and conversely the expectations from the use of the rubric should enhance the learning outcomes for the students. Without this, a rubric can lead to promotion of shallow learning whilst producing conformity and standardisation in the VLE, (Mandills et al 2009). In turn this can create missed learning opportunities for the student as they are only working towards the rubric criteria. There are some criticisms of the use of rubrics in regards to 'validity, reliability and fairness' particularly in relation to students in view of a lack of empirical evidence to support 
effective use of a rubric, (Andrade and Du 2005 p 29). Jonsson and Svingby (2007) propose that effectiveness of rubrics can be examined based on literature at the time of writing. Despite these on-going issues there is growing confidence about the effectiveness of rubrics (Rezaei and Lovorn 2010)

When developing a rubric the lecturer needs to consider the type of assessment being designed eg essay, learning log, discussion board, poster, and whether there is already a marking guide on which to base the rubric. Hence in development of the rubric, Nicol and Mcfarlen-Dick's (2006) seven principles of good feedback should implemented:-

1. Clarify what good performance is

2. Facilitate reflection and self-assessment in learning

3. Deliver high-quality feedback information that helps learners self-correct

4. Encourage teacher-learner and peer dialogue

5. Encourage positive motivational beliefs and self-esteem

6. Provide opportunities to act on feedback

It should be simple to use and the language of the performance indicators should be easily understood by both the lecturers and students (Whittaker, Salend and Duhaney 2001; Wilson and Fairchild 2011). To promote this effect it is critical that the language used in the performance indicators and the categories is transparent and there is no misconception of what is expected from the learning outcomes (Lasater, 2006). Other contributing factors to consider is how the rubric is intended to be used as a feedback mechanism for students, and thereby to continue to improve their comprehension and expectation of the assessment activity (Morgaine, 2010; Frances 2010). When using the rubric as a grading tool and to elicit the engagement of the students through understanding the assessment activity requirements, the main reference to the rubrics for both parties are the differing criteria for each of the performance indicators. These categories have to be accurately represented and achievable. The communication that the rubric gives, enables the students to engage in assessment activity. Hence the use of the language within the rubric must foster a dialogue that works in partnership with the feedback and promotes discussion between the lecturer and the student. Stevens and Levi (2005) sees the rubric as a translator device to gain a level playing field in the learning activity.

The goal of the developing rubric, is to create equal opportunities for the students when engaging with the assessment process and receiving feedback from the lecturer. A result of the changed the learning environment via the VLE for students is to have a constructive influence on student engagement. The VLE gives easy student home-based access with the benefits of developing critical thinking with socialised interaction with others in a learning space (Buckley, et al 2005). A key positive outcome for the lecturers when using the rubric is that the tool being user friendly, it becomes easy to identify the different grading scales that correlate with the performance indicators. This simplifies the marking experience speeding up the process whilst enabling the giving constructive feedback in a timely fashion. It also minimizes the inconsistencies between lecturers and gaining parity in the assessment process. 


\section{Conclusion}

In today's educational environment, the student wants clear guidance and direction to "how is this assessment being graded?" and "what is it that the assessment is asking for?" In return there is increasingly more expectations on the lecturer to engage with a variety of different modes of assessment and to enhance the learning experience of the student. In real terms this means rapid marking and feedback to be ready in a short time frame, therefore the use of a rubric for this purpose is a tool that can facilitate this. However to design an effective rubric requires time and revaluation after each usage. Each rubric should be designed individually to reflect the assessment activity. When starting out it is easier to start simple rather than complex as the road travelled for the rubric is about meeting the needs of the lecturer and the student. The rubric is a grading tool that should communicate the expectation of the assessment activity and used as constructive feedback for the student to feed-forward with the learning concepts obtained from the assessment task.

The performance levels indicators must enable both the lecturer and student to differentiate between levels. Hence the description of these levels needs to be clearly defined and logically sequenced. It should promote recognition of varying levels of performance and encouraging the student to improve and drive own learning to enhance their depth of knowledge. This can be further achieved through the ability to discriminate between performance levels via the use of a range of subjective words in defining these differences. The specificity of the performance indicators needs to demonstrate usefulness, and allow enhanced analysis of the given task.

The development [see Figures 1 and 2] of this rubric was to facilitate fast and effective feedback to feed forward for an online discussion board. It was a way of ensuring that both lecturer and student understood what was required of them. This style of analytic rubric provided the potential for the student to take accountability for their own learning through clear performance criteria. By combining the assessment outcomes with the performance indicators the rubric has been able to provide the students with information regarding what is most important to focus on and where their level and depth of knowledge is in relation to the given assessment. Through reviewing students work and the original rubric against the developing rubric other additional criteria are generated or deleted. This therefore triggered another revision of the rubric which will concentrate on the finer differentiation of levels. How the rubric continues to develop will be dictated by its usage and the revision/evaluation process. In conclusion it be seen that the rubric is not a static thing but a tool that is continually evolving and enhancing the learning process.

\section{References}

Andrade, H., (2005). Teaching with rubrics the good, the bad, and the ugly. College Teaching, 53(1), 27-30.

Andrade, H., Du, Y., (2005). Student perspectives on rubric-referenced assessment. Practical Assessment Research and Evaluation, 10(3), 1-11

Beaglehole, V. (2014) Assessing Writing Using rubrics. Practically Primary. Practically Primary, 19(2), 13-15.

Buckley, K.M., Benya, B., Dudley-Brown, S., (2005). Promoting active learning through on-line discussion board. Nurse Educator, 30(1), 35-36. 
Caulfield-Sloan, M.B., Ruzicka M.F., (2005). The Effect of teachers’ staff development in the use of higher-order questioning strategies on third grade students' rubric science assessment performance. Planning and Changes, 36(3-4), 157 - 175.

Dunbar, N, E., Brooks, C.F., Kubicka-Miller, T., (2006). Oral communication skills in higher education: Using a performance-based Evaluation Rubric to assess communication skills. Innovation Higher Education, 23(2), 115-127.

Fors, U.G.H., Gunning, W.T., (2014). The impact of different scoring rubrics for grading virtual patient -based exams. Journal Education Computing Research, 50(1), 97-119.

Hafner, J., Hafner, P., (2003). Quantitative analysis of the rubric as an assessment tool: an empirical study of student peer-group rating. International Journal of Science Education, 25(12), 1509-1528.

Jonsson, A., Svingby., (2007). The use of scoring rubrics: Reliability, validity and educational consequences. Educational Research Review, 2, 130-144.

Lai, Y.C., Ng, E,M,W., (2012). Using Wikis to develop students teachers' learning, teaching and assessment capabilities. Internet and Higher Education, 14, 15 - 26.

Lasater, K., (2007). Clinical Judgment Development: Using Simulation to Create an Assessment Rubric. Journal of Nursing Education, 46(11), 496 - 503.

Mansilla, V.B., Duraisingh, E.D., Wofle, C.R., and Haynes, C., (2009). Targeted assessment rubric: An empirically grounded rubric for interdisciplinary writing. The Journal of Higher Education, 80(3), 334-353.

Morgaine, W., (2010). Developing Rubrics: lessons learned; Assessing Outcomes and Improving: Tips and tools for Using Rubrics , 11-13. Chicago.

Nicol, D.J., Macfarlane-Dick, D., (2006). 'Formative assessment and self-regulated learning: A model and seven principles of good feedback practice', Studies in Higher Education, 31(2), 199-218.

Nursing and Midwifery Council. (2010). Standards for pre-registration education.

Petkov, D., Petkova, O., (2006). Development of Scoring Rubrics for IS projects as an assessment tool. Information Science and Technology 3, 500 - 509.

Popham, W.J., (1997). What's Wrong - and What's Right- With Rubrics Educational Leadership, 55, 72- 75.

Pucer, P., Trobec, C.I., Zvanut, B., (2014). An information on communication. Technology based approach for acquisition of critical thinking skills. Nursing Education Today, 34 (6) 964-970.

Reddy, Y.M., Andrade, H., (2009). A review of rubric in higher education. Assessment and Evaluation in Higher Education, 35 (4) 435-448.

Rezaei, A.R., Lovorn, M., (2010). Reliability and validity if rubric for assessment through writing. Assessing Writing, 15, 18 -39.

Sadler, B., Andrade, H., (2004). The Writing Rubric. Educational Leadership, 62 (2), 48-52

Song, L., McNary, S.W., (2011). Understanding Students' Online Interaction: Analysis of Discussion Board Postings. Journal of Interactive Online Learning 10 (1) 114.

Stevens, D.D., Levi, A., (2005). Introduction to Rubrics. An assessment tool to save grading time, convey effective feedback and promote student learning. Stylus Publishing, LLC . Virginia 
Truemper, C.M., (2004). Using scoring rubrics to facilitate assessment and evaluation of graduate level nursing students. Journal of Nursing Education, 43, (12) 562-4.

Vallino, J., (2008). Workshop- Rubrics : Start to Finish. Proceedings of 2008 Frontiers in Education Conference, Saratoga Springs, NY.

Whittaker, C.R., Salend, S.J., Duhaney, D., (2001). Creating instructional rubrics for inclusive classrooms. Teaching Exceptional Children, 34(2), 8-13.

Wilson, M., Fairchild, C., (2011). Collaborative learning and the importance of the discussion board. Journal of Diagnostic Medical Sonography, 27(1), 45-51. 